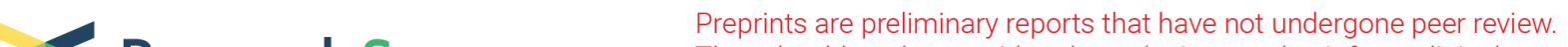 $\begin{array}{ll}\text { Research Square } & \text { They should not be considered conclusive, used to inform clinical practice, } \\ \text { or referenced by the media as validated information. }\end{array}$
}

\section{The Oxygenation Module - The Missing Link in Using Sleep Apnea Devices to Treat COVID-19 Pneumonia at Home}

\section{Dmitrijs Bliznuks ( $\nabla$ dmitrijs.bliznuks@rtu.lv)}

RTU DITF: Rigas Tehniska universitate Datorzinatnes un informacijas tehnologijas fakultate https://orcid.org/0000-0003-4252-9220

\section{Svjatoslavs Kistkins}

Paul Stradins Clinical University Hospital: Paula Stradina Kliniska Universitates Slimnica

Jevgēnijs Teličko

University of Latvia: Latvijas Universitate

\section{Vadims Geža}

University of Latvia: Latvijas Universitate

\section{Ģirts Zāǵeris}

University of Latvia: Latvijas Universitate

\section{Artis Svaža}

Paula Stradina Kliniska Universitates Slimnica

\section{Emil Syundyukov}

University of Latvia: Latvijas Universitate

\section{Mārtinš Purenkovs}

Paul Stradins Clinical University Hospital: Paula Stradina Kliniska Universitates Slimnica

\section{Dana Zeme}

Paul Stradins Clinical University Hospital: Paula Stradina Kliniska Universitates Slimnica

\section{Solveiga Jēkabsone}

Paul Stradins Clinical University Hospital: Paula Stradina Kliniska Universitates Slimnica

\section{Dace Žentina}

Paul Stradins Clinical University Hospital: Paula Stradina Kliniska Universitates Slimnica

\section{Valdis Pirāgs}

Paul Stradins Clinical University Hospital: Paula Stradina Kliniska Universitates Slimnica

\section{Immanuels Taivans}

University of Latvia: Latvijas Universitate

\section{Research}

Keywords: Sleep apnea, COVID-19, Critical Care, Non-invasive ventilation, homecare 
Posted Date: October 22nd, 2021

DOl: https://doi.org/10.21203/rs.3.rs-948467/v1

License: (c) (i) This work is licensed under a Creative Commons Attribution 4.0 International License. Read Full License

Version of Record: A version of this preprint was published at BioMedical Engineering OnLine on February 4th, 2022. See the published version at https://doi.org/10.1186/s12938-022-00982-z. 


\section{Abstract}

Background: The study aims at solving the problem with the limitations of the homecare CPAP equipment such as sleep apnea devices in the treatment of COVID-19 pneumonia. By adding an advanced, rapid-to-produce oxygenation module to CPAP device we allow distributing healthcare at all levels, reducing the load on intensive care units, promoting treatment in the early stages at homecare. A significant part of the COVID-19 pneumonia patients requires not only an oxygen supply but also additional air pressure. Existing home care devices are able to create precise positive airway pressure but cannot precisely measure supplied oxygen concentration. Either uses uncertified and potentially unsafe mechanisms.

Results: The developed system allows using certified and widely available CPAP (constant positive airway pressure) devices to perform the critical function of delivering pressure and oxygen to airways. CPAP device is connected to the designed add-on module that can provide predefined oxygen concentration in a precise and stable manner. Clinical test results include data from 12 COVID-19 positive patients. The device has been compared against certified NIV (non-invasive) equipment under 6-20 hPa pressure and $30-70 \% \mathrm{FiO} 2$. Tests have proved that the developed system can achieve the same $\mathrm{SaO} 2$ $(p=0.93)$ and $\mathrm{PaO} 2(p=0.80)$ levels as NIV with clinically insignificant differences. Test results show that the designed system can substitute NIV equipment for a significant part of COVID-19 patients while leaving existing NIV devices for unstable and critical patients. The system has been designed to be massproduced while having medically certified critical components.

Conclusion: The clinical testing of the new device for oxygen supplementation of patients treated using simple CPAP devices looks promising and could be used for the treatment of COVID-19 pneumonia.

\section{Background}

In the majority of cases, COVID-19 runs with inflammation in the upper airways and manifests with symptoms like dry cough, subfebrile or febrile temperature, and resolves in several days. Some patients [1] develop pneumonia with symptoms of hypoxia and decreased level of Sp02. Therefore, the management of COVID-19 caused type 1 respiratory failure patients includes the administration of additional oxygen and prevention of distal airway and alveolar collapse [2,3]. These options can be maintained by using non-invasive ventilation (NIV) applying positive end-expiratory pressure (PEEP). The existing intensive care NIV devices and high flow nasal cannula (HFNC) currently are used in treatment type 1 respiratory failure in patients with COVID-19 pneumonia [4-6]. However, shortages in the number of available NIV or HFNC, as well as high costs of the devices, provide several significant limitations, especially during the outbreak when time and expenses are crucial [7]. For this purpose, a cheap and rapidly produced solution must meet the criteria of clinical efficacy similar to the efficacy of NIV or HFNC.

The simplest way to promote PEEP is to use devices that are designed for the treatment of sleep apnea syndrome - CPAP devices that keep slightly positive pressure in airways, so preventing airways collapse 
at the end of expiration. These instruments also allow the administration of additional oxygen by introducing it into the inspiratory port or directly into the face mask [8].

However, this oxygen administration does not allow precise measurement of oxygen concentration in inhaled air because of fluctuations of oxygen level due to continuous air movements in the inspiratory port. At the same time a proper oxygen concentration is significant for the calculation of alveolar-arterial gradient for oxygen, which is an indicator of permeability of the alveolo-capillary membrane, or in other words - an indicator of the level of lung respiratory function loss. Continuous measurement of this index allows monitoring the clinical condition, providing rapid response in deterioration of the disease [9].

Therefore, we have created the add-on device for CPAP instruments allowing us to deliver the precise oxygen concentration to the patient. The study aimed to modify CPAP devices and clinically investigate the efficacy of the proposed solution by comparing it with current existing NIV devices.

\section{Methods}

\section{Ventilator description}

The proposed device has been designed as an add-on to the CPAP device that is certified to provide an automatically controllable air pressure supply to the patient. The overall scheme of the modified system is shown below in figure 1.A.

The device allowed controlling oxygen supply to the patient's inhaled air in the FiO2 range of 21-95\%. Supplied air pressure and moisture have been controlled by a certified CPAP device. During the development stage, two versions of the CPAP add-on have been designed: draft prototype to prove the concept (Fig. 1.B.) and final prototype ready to be mass-produced (Fig. 1.C).

The microcontroller based system monitors oxygen concentration at the output of the tank and adjusts the oxygen supply to keep the FiO2 at the set level. Clinicians can see the current FiO2 level on the LCD touchscreen and can change it according to therapy. The device has alarm and logging capabilities to monitor patients' condition and store data for further analysis. The device applies to Type B (Body) class - "No direct physical contact with the patient". And to the product class IIA as for "Directive 93/42/EEC". The device served as an add-on to the existing certified CPAP equipment (eg. Löwenstein medical Prisma Smart). The add-on has been electrically operated, with no direct contact with patients or operators (health care personnel). Oxygen flow control has been provided by using a medical-grade flow meter as an intermediate device.

To obtain a controllable oxygen supply to the patient, it is essential to do precise measurements of oxygen concentration in the flow. However, oxygen concentration may vary significantly across the crosssection of the flow channel (pipe) if gases are not premixed. For this reason, numerical simulations were carried out for different mixing setups to establish a flow where oxygen concentration is precisely measurable. The simplest way to supply oxygen is to make a straight oxygen pipe connection to the main 
CPAP flow channel. Numerical simulation results of oxygen concentration reveal high inhomogeneity. Xtype mixer appropriately performs in the terms of oxygen homogeneity, but it greatly increases hydraulic resistance $(+15 \%)$. Similar questions have also been raised in literature adding a viral/bacterial filter proximally to patient [10]. To deal with this problem, a custom mixer has been designed that allowed mixing oxygen with homogeneity $>99.5 \%$ and low hydraulic resistance $(+5 \%)$. An additional challenge for the add-on device creation was reaching stable concentration levels of oxygen at any breath phase. That was achieved by the incorporation of a buffer tank into the inhalation line. Multiple simulations have been performed to find an optimal volume and shape of the tank.

\section{Ventilator testing in patients with COVID-19 pneumonia}

The clinical testing of the new device has been realized by comparing the efficiency and safety of the new CPAP supplemental oxygen delivery system with the efficiency of a non-invasive ventilator (NIV) in the CPAP/PEEP mode. Two Intensive care ventilators have been used - Philips Respironics V60 and Maquet Seervo - AIR in CPAP mode for one hour and then changed therapy to APAP Lowenstein medical Prisma Smart connected to newly made extra oxygen delivery device.

Hypoxaemic patients, who received just oxygen therapy or NIV therapy in CPAP mode have been included in the study.

The study was evaluated and received permission from the local Ethics committee of the PSCUH. Patients have been informed that a catheter will be inserted into their artery to get blood samples. The patient's characteristics are given in Table 1. 
Table 1

Patients data

\begin{tabular}{|lllllll|}
\hline Patient ID & Gender & Age, years & $\mathrm{SpO}_{2}$ & $\mathrm{AaDO}_{2}$ & $\mathrm{PaCO} 2$ & PEEP \\
\hline P1 & M & 80 & 95 & 372 & 37 & 5 \\
\hline P2 & M & 77 & 94 & 175 & 31 & 5 \\
\hline P3 & M & 63 & 94 & 171 & 31 & 9 \\
\hline P4 & M & 44 & 97 & 155 & 36 & 5 \\
\hline P5 & M & 42 & 95 & 92 & 35 & 6 \\
\hline P6 & M & 44 & 95 & 165 & 37 & 5 \\
\hline P7 & F & 33 & 98 & 73 & 48 & 6 \\
\hline P8 & M & 53 & 96 & 87 & 38 & 5 \\
\hline P9 & M & 53 & 95 & 333 & 41 & 7 \\
\hline P10 & M & 62 & 92 & 388 & 44 & 12 \\
\hline P11 & F & 79 & 96 & 163 & 33 & 6 \\
\hline P12 & M & 78 & 95 & 178 & 27 & 5 \\
\hline
\end{tabular}

The majority of patients were males (83\%). The table shows that patients were selected in stable condition, their transcutaneous oxygen saturation was kept at least above $92 \%$ by adjusting both $\mathrm{FiO} 2$ and PEEP at necessary levels.

Inclusion criteria were age $>18$, hypoxaemia $<92 \%$ and $<88 \%$ in patients with risk of hypercapnic respiratory failure. Exclusion criteria were contraindications for noninvasive ventilation (e.g. unstable conditions of upper airways, aspiration risks) and clinical deterioration of patient condition that was decided by study performing physician.

Before the experiment, the arterial catheter has been inserted into a patient's radial artery and the first arterial blood probe has been taken after hypoxaemia was corrected. The examination lasted one hour, each 15 minutes the blood probe was repeated and checked for ABG parameters. Straight after or after 15 minute break patients have been connected to the new CPAP supplemental oxygen delivery system and FiO2 and PEEP levels have been set similar to the previous instrument. FiO2 and PEEP levels, if necessary, were corrected regarding arterial blood gas analysis and SpO2 measurements.

SpO2 has been monitored continuously, blood gas analysis has been repeated every 15 minutes $(\mathrm{pH}$, $\mathrm{PaO} 2, \mathrm{PaCO} 2, \mathrm{HCO}-, \mathrm{SaO} 2)$, blood pressure, heart rate, respiratory rate, with the help of an additional sensor FiO2. With each subsequent device, the PEEP size has been selected the same as with the previous device or its modification. 
Research data has been processed using 'MS Excel' and 'SPSS' software by repeated-measures analysis of variance ('ANOVA'). The obtained data ( $\mathrm{pH}, \mathrm{PaO} 2, \mathrm{PaCO} 2, \mathrm{HCO} 3-, \mathrm{SaO} 2$, blood pressure, heart rate, respiratory rate, with the help of an additional sensor FiO2) have been compared between all groups.

\section{Results}

\section{Bench testing}

As shown in the methods section, after performing numerical simulations of oxygen mixing performance, the final design with the buffer tank has been used for building a prototype. In figure 2 oxygen concentration with and without buffer tank can be seen. The resulting oxygen concentration fluctuations with a buffer tank were $<1 \%$.

The plot has been obtained by using a prototype device set at $6 \mathrm{hPa}$ positive pressure and a healthy person. While the mask is properly attached and there are no breathing abruptions, the system could keep oxygen concentration accuracy within $1 \%$, even if the character of the patient's breathing changes. Without a buffer tank oxygen concentration changes according to breathing frequency. Right after switching the system or after reapplying the mask, it might take up to a minute, while concentration reaches the desired level and stabilizes. Such effects do not affect therapy and are acceptable as seen in the clinical results section below.

\section{Clinical testing in patients with COVID-19 pneumonia}

Totally 16 patients with COVID-19 pneumonia have been enrolled on a clinical trial and 12 of them have been included. The characteristics of patients included in a clinical trial are shown in the table below. Two patients have been excluded due to intolerance to a face mask, while the third patient has been expelled due to clinical deterioration receiving primarily only NIV. The fourth patient has been excluded due to arterial catheter thrombosis.

To compare the effectiveness of the new oxygen supply system (CPAP+) with a standard non-invasive ventilator (NIV) we used a repeated-measures analysis of variance (ANOVA).

Figure 3.A allows comparing necessary concentrations of oxygen in the inhalation line (FiO2) which were set on two devices to keep the stable oxygen saturation (SaO2). The figure 4 shows that FiO2 levels did not differ significantly in the majority of patients. Only in two cases when changing from one instrument to another different oxygen concentration had to be set. Fig. 3.B. reflects the levels of carbon dioxide measured in arterial blood (PaCO2) Graph shows that two patients, P7 and P10 had C02 concentrations above $40 \mathrm{mmHg}$, indicating carbon dioxide retention. At the same time breathing with aid of any of both devices did not change high $\mathrm{CO} 2$ values.A significant difference between $\mathrm{CO} 2$ values (Fig. 3.B) in patient 3 probably occurred due to hypocapnia induced by hyperventilation and did not depend on the device used. 
Most precisely the effectiveness of oxygen supplementation may be checked by analyzing arterial blood gases. The most sensitive index is partial oxygen pressure. Figures 4.A-B demonstrate $\mathrm{PaO} 2$ levels in individual patients being connected to both tested devices. Significant differences in Pao2 and $\mathrm{SaO} 2$ levels have been presented only in two patients. In these cases, a lower level of Pao2 has been observed in the trial with the CPAP+ device. However, as can be seen from the graph, in other patients the situation can be the opposite - higher levels of $\mathrm{PaO} 2$ with $\mathrm{CPAP}+$ device. Taken together, the comparison between two devices in all patients cohorts show no significant differences between $\mathrm{PaO} 2$ and $\mathrm{SaO} 2$ values.

(Fig. 4.C-D)

The necessary FiO2 for each patient depended on the severity of their disease. A precise indicator of the effectiveness of gas exchange is the alveolar-arterial gradient of oxygen (AaDO2). Fig. 5 shows the regression analysis between $\mathrm{FiO} 2$ and alveolar-arterial gradient. Graphs representing data obtained with both devices (NIV - Fig. 6.a.; CPAP+ - Fig. 6.b) show high predictiveness levels.

Summary of significant differences between most important indices measured in two trials is presented in Table 2, showing $p$ values. The full table of all measured and calculated indices is available in Annex.

Table 2

p-values characterizing the differences between the mean values of indices measured using NIV and CPAP+ instruments in individual patients. Values indicating significant differences are marked with bold

\begin{tabular}{|llllll|}
\hline Pac. ID & FiO2 & SaO2 & PaO2 & PA-aO2 & PaCO2 \\
\hline P1 & 0.050 & 0.001 & 0.001 & 0.136 & 0.801 \\
\hline P2 & 0.927 & 0.134 & 0.251 & 0.765 & 0.801 \\
\hline P3 & 0.785 & 0.001 & 0.006 & 0.787 & 0.0001 \\
\hline P4 & 0.649 & 0.198 & 0.284 & 0.722 & 0.704 \\
\hline P5 & 0.414 & 0.388 & 0.208 & 0.570 & 1.000 \\
\hline P6 & 0.716 & 0.829 & 1.000 & 0.776 & 0.135 \\
\hline P7 & 0.088 & 0.388 & 0.236 & 0.119 & 0.211 \\
\hline P8 & 0.011 & 0.198 & 0.128 & 0.022 & 0.705 \\
\hline P9 & 0.002 & 0.829 & 0.939 & 0.755 & 0.170 \\
\hline P10 & 0.206 & 0.282 & 0.514 & 0.190 & 0.170 \\
\hline P11 & 0.240 & 0.517 & 0.514 & 0.272 & 0.801 \\
\hline P12 & 0.927 & 0.088 & 0.128 & 0.842 & 0.614 \\
\hline
\end{tabular}

\section{Discussion}


The results of this study showed no statistically significant clinical differences between NIV and modified $\mathrm{CPAP}+$, proposing a further discussion regarding the cost-effectiveness of the solution during the state of emergency.

It would be appropriate to compare currently existing three available types of devices in CPAP mode: the authors proposed home-care APAP/CPAP modification in comparison with two types of NIV device: hospital equipment and both hospital/home care devices.

In the table below (Table 3), CPAP+ modification is 4 to 15 times cheaper than alternative solutions. As the clinical study shows, device efficiencies are statistically similar to ICU-NIV. It is worth mentioning that the CPAP+ modification has been clinically tested only FiO2 $<70 \%$ while ICU-NIV equipment reaches $100 \%$ oxygen concentration. However, preclinical results showed $\mathrm{FiO} 2>95 \%$. It must be taken into account that we have aimed to develop a cost-effective device that can reduce the load on existing ICU-NIV devices.

Table 3

Comparison of three available types of devices in CPAP mode

\begin{tabular}{|c|c|c|c|}
\hline & $\begin{array}{l}\text { Our } \\
\text { CPAP+ } \\
\text { device }\end{array}$ & $\begin{array}{l}\text { NIV in } \\
\text { hospitals } \\
\text { (ICU-NIV) }\end{array}$ & $\begin{array}{l}\text { NIV in hospitals } \\
+ \text { home care }\end{array}$ \\
\hline Full set price in EUR & 800 & $\begin{array}{l}10,000- \\
13,000\end{array}$ & $3,000-7,000$ \\
\hline $\begin{array}{l}\text { Oxygen supply from the central gas system without a } \\
\text { flow meter }\end{array}$ & + & + & - \\
\hline $\begin{array}{l}\text { Oxygen supply from the central gas system with a flow } \\
\text { meter, up to } 15 \mathrm{I} / \mathrm{min} \text {. }\end{array}$ & + & + & + \\
\hline Oxygen supply from low-pressure oxygen concentrators & + & - & + \\
\hline Maximal achievable FiO2 & $\begin{array}{l}70 \%- \\
95 \%\end{array}$ & $100 \%$ & $\begin{array}{l}\text { Depending on } \\
\text { PEEP }\end{array}$ \\
\hline Oxygen concentration is displayed on a screen. & + & + & - \\
\hline $\begin{array}{l}\text { Ability to control and regulate oxygen concentration } \\
\text { independently from the applied pressure }\end{array}$ & + & + & - \\
\hline Necessary technical and electrical safety checks. & $\begin{array}{l}\text { Once a } \\
\text { year }\end{array}$ & $\begin{array}{l}\text { Once a } \\
\text { year }\end{array}$ & Not required \\
\hline
\end{tabular}

The proposed benefits of the modification of the home CPAPs may be defined as low costs per one unit (800 EUR per home CPAP and add-on comparing to 10,000 EUR per ICU-NIV); rapid production and distribution (2-3 weeks vs 3-5 months); redirection of home-CPAP devices for the use in chronic conditions, such as sleep apnea after the outbreak. The potential cost-effectiveness may be significantly higher if the sleep apnea device could be rearranged for the patients that are primarily diagnosed with 
OSA. At the same time, strategic reserves of CPAP devices may be stored in hospitals to be ready for the new wave.

Industrial enterprises and scientists also tried to succeed in development of low-cost ventilators [11-15]. Despite the fact that Garmendia et al [16] designed and clinically tested even much cheaper CPAP machines proposing 70-80 EUR instead of 600 EUR, the next study shows that early CPAP intervention could result in a potentially viable treatment option for patients only during the first days of hospitalisation [17]. Garmendia's CPAP device could be used in the early stage of the disease while moderate requires significant additional oxygen therapy [18]. Pandor et al previously compared the costeffectiveness of the prehospital-CPAP without a proper oxygen delivery arguing that the results of the study were uncertain [19]. The proposed additional solution may enhance the efficacy of the Garmendia CPAP devices, providing even cheaper analogues of NIV devices for more severe patients requiring higher oxygen concentration.

During the first outbreak Engineers of UK Formula 1 have developed a CPAP machine with the distribution of oxygen and positive airway pressure to patients $[20,21]$. The F1 CPAP device mixes gases in a proper concentration based on the Venturi effect thus resulting in a proper gas formation with much predictable FiO2 concentration. However, this device also requires an additional outsourced oxygen sensor and a pressure valve promoting $15-20 \mathrm{mmH} 20$ pressure. A cost-effective solution met several disadvantages such as high oxygen expenditures due to the construction of the equipment with a further load on the oxygen supply chain in the hospital. A high oxygen expenditure promotes overload of hospital medical gas system [22,23] As the experience showed, frequently CPAP equipment can be used at home, additionally relieving the medical infrastructure $[24,25]$ Moreover, it facilitates saving of financial means, because the acquisition of a large number of intensive therapy lung ventilators is not needed. For this purpose the proposed CPAP modification can use an external oxygen delivery system such as oxygen concentrators, reducing the load on the oxygen supply chain in the hospital.

Despite the advantage of this method of oxygen delivery there were some observations and raising questions about the usage of the device and its operation:

As mentioned in the previous sections, the device has accuracy limitations during sudden flow changes, for example reapplying the mask. The device buffer tank volume has been calculated to smooth fluctuations during inhale and exhale phase when flow change stays below a certain limit. If the mask is removed, flow increases rapidly and since oxygen flow is limited, the buffer is emptied fast and oxygen concentration drops below a preset level. The same effects could be observed if the mask is not applied properly and there are occasional false-air situations. Existing NIV devices premix oxygen before performing pressure/flow control therefore can keep constant concentration-independent to the mask application.

Other limitations of the developed system include the inability to transport patients since the device has no autonomous power source. The device is not delivering additional breathing measurements like ICU ventilator: tidal volume, minute ventilation, peak pressure, flow, volume, and pressure waves. The current 
design requires significant time to dismount air pathways for sterilization. Nevertheless, sterilization by using special gases is possible.

Clinical testing of the new CPAP supplemental oxygen delivery system has shown that this device allows enriching the air with oxygen up to $70 \%$ during CPAP therapy (higher concentrations have only been tested pre-clinically). Comparison with a standard non-invasive ventilator (NIV) working in CPAP mode has shown that most important indices of gas exchange, like $\mathrm{PaO} 2$ and $\mathrm{PaCO} 2$, did not change significantly when switching the patients from breathing with aid of NIV instrument to CPAP+.

Two cases ( $\mathrm{P} 1$ and $\mathrm{P} 3$ ) showing significant differences in $\mathrm{PaO} 2$ between two devices evidently have been connected with changes in the patient's condition and did not depend on the instrument. The same concerns the differences in $\mathrm{PaCO} 2$ in patient 3 , when obviously the cause was hyperventilation.

\section{Conclusions}

The clinical testing of the new device for oxygen supplementation of patients treated using simple CPAP devices looks promising and could be used for treatment of covid-19 pneumonia.

\section{Abbreviations}

AaDO2 - Alveolar-arterial gradient of oxygen

ABG - Arterial blood gases

APAP - Automatic positive airway pressure

COVID-19 - Coronavirus disease 2019

CPAP - Continuous positive airway pressure

FiO2 - Fraction of inspired oxygen

HFNC - High flow nasal cannula

ICU - Intensive care unit

LCD - Liquid-crystal display

NIV - Non-invasive ventilation

OSA - Obstructive sleep apnea

$\mathrm{PaO} 2$ - Partial pressure of oxygen in arterial blood

PaCO2 - Partial pressure of carbon dioxide pressure in arterial blood 
PEEP - Positive end-expiratory pressure

PSCUH - Paul Stradins Clinical University Hospital

SaO2 - Arterial oxygen saturation

Sp02 - Oxygen saturation provided by pulseoxymetry

\section{Declarations}

Ethical Approval and Consent to participate: The study was evaluated and received permission from the local Ethics committee of the PSCUH. Nr. 261120-10L

Consent for publication: We grant exclusive rights on royalty-free basis to BMC Publishing Group Ltd ("BMC") its licensees and where the relevant Journal is co-owned by BMC to the co-owners of the Journal, to publish the Work in Biomedical Engineering Online and to exploit all rights.

Availability of supporting data: Not applicable.

Competing interests: No competing interests.

Funding: Grant “VPP-COVID-2020/1-0025” from Latvian Council of Science

Authors' contributions: All authors contributed and reviewed the manuscript. DB, VG, JT, G̦Z, ES participated in prototype design and bench tests, SK, AS, MP, SJ, DZ, DŽ participated in a clinical trial, VP and IT triple checked all data and provided statistical support.

Acknowledgements: We would like to thank the following for their helpful comments: University of Latvia: Maksims Mastalers, Aleksandra Podhvatilina, Sergejs Lobanovs, Kristina Sauliusa, Olga Matosova, Kaspars Eglītis. We would like also to thank Marek Zevalds (VRGO Ltd), Jana Višṇevska (Longenesis Ltd), Arnis Salms (Institute of Electronics and Computer Science), Jānis Zaharns and Jurijs Jonass. We would very much like to thank Ilze Ābolina (PSCUS) for the study coordination.

\section{References}

1. Mason RJ. Pathogenesis of COVID-19 from a cell biology perspective. Eur Respir J. 2020 Apr 16;55(4):2000607. doi: 10.1183/13993003.00607-2020. PMID: 32269085; PMCID: PMC7144260.

2. Brusasco C, Corradi F, Di Domenico A, Raggi F, Timossi G, Santori G, Brusasco V; Galliera CPAPCovid-19 study group; collaborators of the Galliera CPAP-COVID-19 study group are. Continuous positive airway pressure in COVID-19 patients with moderate-to-severe respiratory failure. Eur Respir J. 2021 Feb 17;57(2):2002524. doi: 10.1183/13993003.02524-2020. PMID: 33033151; PMCID: PMC7545055. 
3. Tobin MJ. Basing Respiratory Management of COVID-19 on Physiological Principles. Am J Respir Crit Care Med. 2020 Jun 1;201(11):1319-1320. doi: 10.1164/rccm.202004-1076ED. PMID: 32281885; PMCID: PMC7258630.

4. Gürün Kaya A, Öz M, Erol S, Çiftçi F, Çiledağ A, Kaya A. High flow nasal cannula in COVID-19: a literature review. Tuberk Toraks. 2020 Jul;68(2):168-174. English. doi: 10.5578/tt.69807. PMID: 32755117.

5. Mellado-Artigas R, Ferreyro BL, Angriman F, Hernández-Sanz M, Arruti E, Torres A, Villar J, Brochard L, Ferrando C; COVID-19 Spanish ICU Network. High-flow nasal oxygen in patients with COVID-19associated acute respiratory failure. Crit Care. 2021 Feb 11;25(1):58. doi: 10.1186/s13054-02103469-w. PMID: 33573680; PMCID: PMC7876530.

6. Carter C, Aedy H, Notter J. COVID-19 disease: Non-Invasive Ventilation and high frequency nasal oxygenation. Clinics in Integrated Care. 2020;1:100006. doi:10.1016/j.intcar.2020.100006

7. Ranney ML, Griffeth V, Jha AK. Critical Supply Shortages - The Need for Ventilators and Personal Protective Equipment during the Covid-19 Pandemic. N Engl J Med. 2020 Apr 30;382(18):e41. doi: 10.1056/NEJMp2006141. Epub 2020 Mar 25. PMID: 32212516.

8. Intensive Care Society. 2020. Use of continuous positive airway pressure (CPAP) for COVID-19 positive patients. https://icmanaesthesiacovid-19.org/news/use-of-cpap-for-covid-19-positivepatients Date last updated: March 30 2020. Date last accessed: March 152021

9. Gabrielli M, Esperide A, Valletta F, Giancristofaro F, Santoro M, Santarelli L, Franceschi F. Relationship Between Arterial-Alveolar Oxygen Gradient, Mortality and Admission to Intensive Care Unit in Severe Covid-19 Related Pneumonia: A Pilot Study. Biomedical journal of Scientific and technical research, 2020, Vol31, Iss1, 23864-68

10. Carteaux G, Pons M, Morin F, Tuffet S, Lesimple A, Badat B, Haudebourg AF, Perier F, Deplante Y, Guillaud C, Schlemmer F, Fois E, Mongardon N, Khellaf M, Jaffal K, Deguillard C, Grimbert P, Huguet R, Razazi K, de Prost N, Templier F, Beloncle F, Mercat A, Brochard L, Audard V, Lim P, Richard JC, Savary D, Mekontso Dessap A. Continuous positive airway pressure for respiratory support during COVID-19 pandemic: a frugal approach from bench to bedside. Ann Intensive Care. $2021 \mathrm{Mar}$ 2;11(1):38. doi: 10.1186/s13613-021-00828-2. PMID: 33655452; PMCID: PMC7924341.

11. MIT. MIT-based team works on rapid deployment of open-source low-cost ventilator. news.mit.edu/2020/ventilator-covid-deployment-open-source-low-cost-0326. Date last updated: March 26 2020. Date last accessed: March 152021

12. Nvidia. NVIDIA Chief Scientist Releases Low-Cost, Open-Source Ventilator Design. blogs.nvidia.com/blog/2020/05/01/low-cost-open-source-ventilator-nvidia-chief-scientist. Date last updated: May 1 2020. Date last accessed: March 152021

13. Dex. Emergency lung ventilator. dex-ic.com/emergency-lung-ventilator. Date last updated: July 27 2020. Date last accessed: March 152021

14. Suzumura EA, Zazula AD, Moriya HT, Fais CQA, Alvarado AL, Cavalcanti AB, Rodrigues RG. Challenges for the development of alternative low-cost ventilators during COVID-19 pandemic in 
Brazil. Rev Bras Ter Intensiva. 2020 Jul-Sep;32(3):444-457. doi: 10.5935/0103-507X.20200075. PMID: 33053036; PMCID: PMC7595729.

15. Vasan A, Weekes R, Connacher W, Sieker J, Stambaugh M, Suresh P, Lee DE, Mazzei W, Schlaepfer E, Vallejos T, Petersen J, Merritt S, Petersen L, Friend J. MADVent: A low-cost ventilator for patients with COVID-19. Med Devices Sens. 2020 Jun 5:e10106. doi: 10.1002/mds3.10106. Epub ahead of print. PMID: 32838208; PMCID: PMC7300530

16. Garmendia O, Rodríguez-Lazaro MA, Otero J, Phan P, Stoyanova A, Dinh-Xuan AT, Gozal D, Navajas D, Montserrat JM, Farré R. Low-cost, easy-to-build noninvasive pressure support ventilator for underresourced regions: open source hardware description, performance and feasibility testing. Eur Respir J. 2020 Jun 4;55(6):2000846. doi: 10.1183/13993003.00846-2020. PMID: 32312862; PMCID: PMC7173672.

17. Ashish A, Unsworth A, Martindale J, Sundar R, Kavuri K, Sedda L, Farrier M. CPAP management of COVID-19 respiratory failure: a first quantitative analysis from an inpatient service evaluation. BMJ Open Respir Res. 2020 Nov;7(1):e000692. doi: 10.1136/bmjresp-2020-000692. PMID: 33148777; PMCID: PMC7643430.

18. Attaway AH, Scheraga RG, Bhimraj A, Biehl M, Hatipoğlu U. Severe covid-19 pneumonia: pathogenesis and clinical management. BMJ. 2021 Mar 10;372:n436. doi: 10.1136/bmj.n436. PMID: 33692022.

19. Pandor A, Thokala P, Goodacre S, Poku E, Stevens JW, Ren S, Cantrell A, Perkins GD, Ward M, PennAshman J. Pre-hospital non-invasive ventilation for acute respiratory failure: a systematic review and cost-effectiveness evaluation. Health Technol Assess. 2015 Jun;19(42):v-vi, 1-102. doi: 10.3310/hta19420. PMID: 26102313; PMCID: PMC4781299..

20. Mahase E. Covid-19: Mercedes F1 to provide breathing aid as alternative to ventilator. BMJ. 2020 Mar 30;368:m1294. doi: 10.1136/bmj.m1294. PMID: 32229575.

21. Singer M, Shipley R, Baker T, Cowell A, Brealey D, Lomas D. The UCL Ventura CPAP device for COVID19. Lancet Respir Med. 2020 Nov;8(11):1076-1078. doi: 10.1016/S2213-2600(20)30422-7. Epub 2020 Sep 21. PMID: 32971017; PMCID: PMC7505625.

22. BBC. Covid-19: Southend Hospital oxygen supply reaches 'critical' situation. https://www.bbc.com/news/uk-england-essex-55615591 Date last updated: January 11 2021. Date last accessed: March 162021.

23. American Association for Respiratory Care. Additional Ventilators May Pose a Risk to Hospital Gas Systems. https://www.aarc.org/additional-ventilators-may-pose-risk-to-hospital-gas-systems/ Date last updated: April 13 2020. Date last accessed: March 162021.

24. Pavwoski P, Shelgikar AV. Treatment options for obstructive sleep apnea. Neurol Clin Pract. 2017 Feb;7(1):77-85. doi: 10.1212/CPJ.0000000000000320. PMID: 29849228; PMCID: PMC5964869.

25. Gottlieb DJ, Punjabi NM. Diagnosis and Management of Obstructive Sleep Apnea: A Review. JAMA. 2020 Apr 14;323(14):1389-1400. doi: 10.1001/jama.2020.3514. PMID: 32286648. 


\section{Figures}
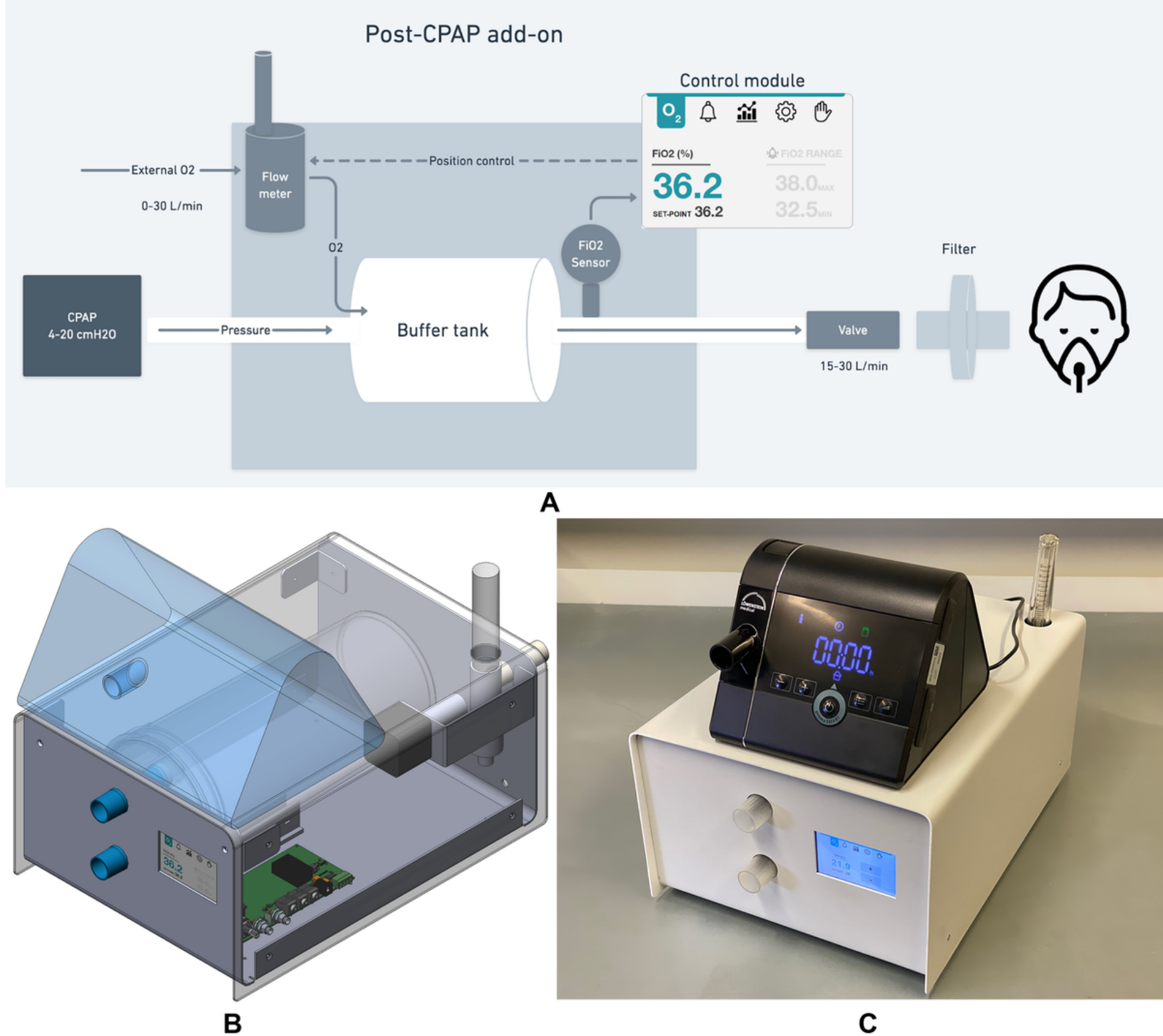

A

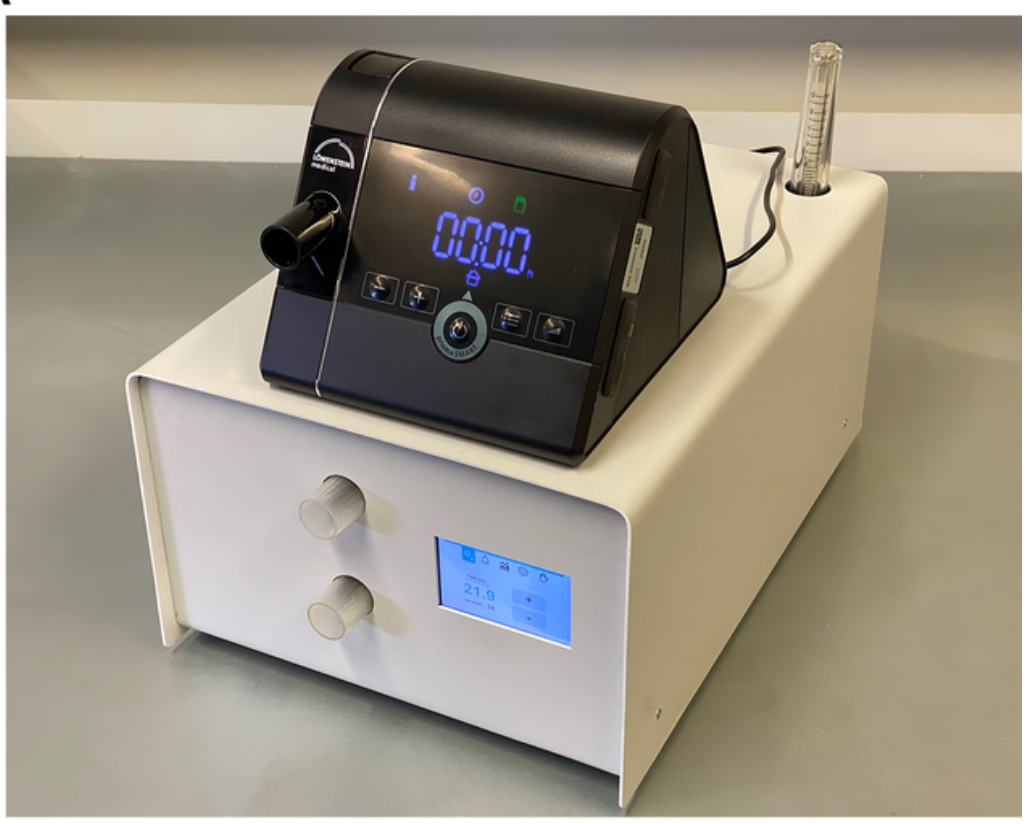

C

Figure 1

A. The scheme of the modification of a certified CPAP device. B. Device 3D model C. The final metal enclosure with CPAP device on top 


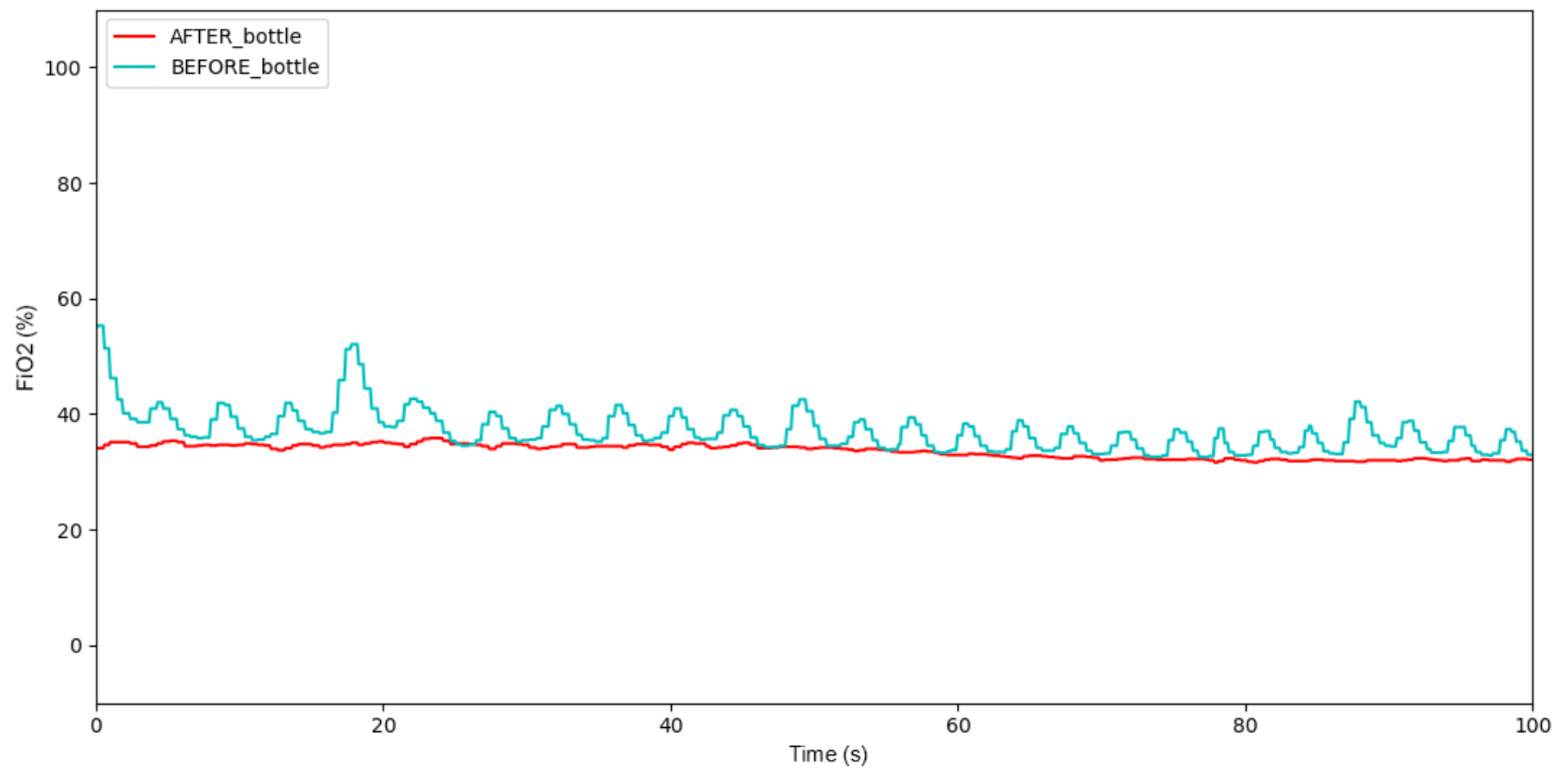

Figure 2

FiO2 measurements in two oxygen sensor locations: before (blue line) and after (red) the buffer tank under $6 \mathrm{hPa}$ pressure

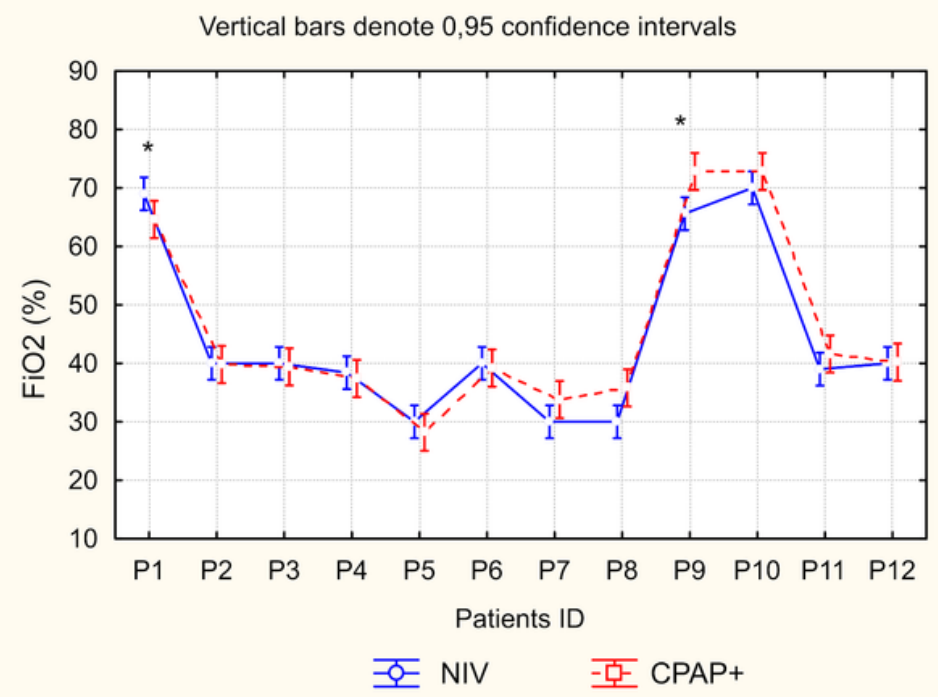

A

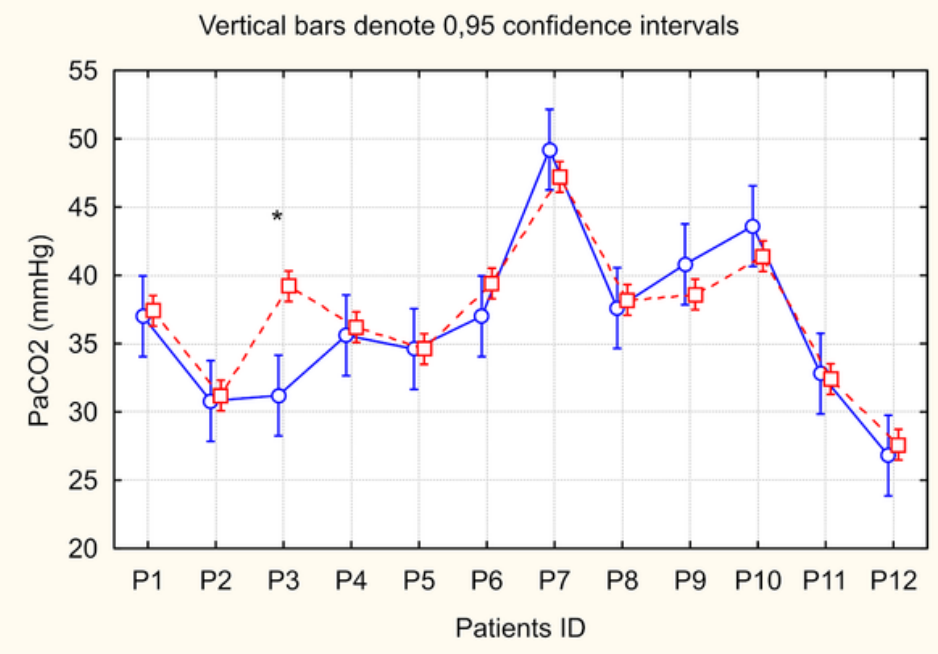

호- NIV 枯 CPAP+

B

\section{Figure 3}

A FiO2 levels necessary to keep oxygen saturation at normal levels in individual patients using two oxygen delivery systems. B. PaCO2 levels in individual patients treated with two compared devices 


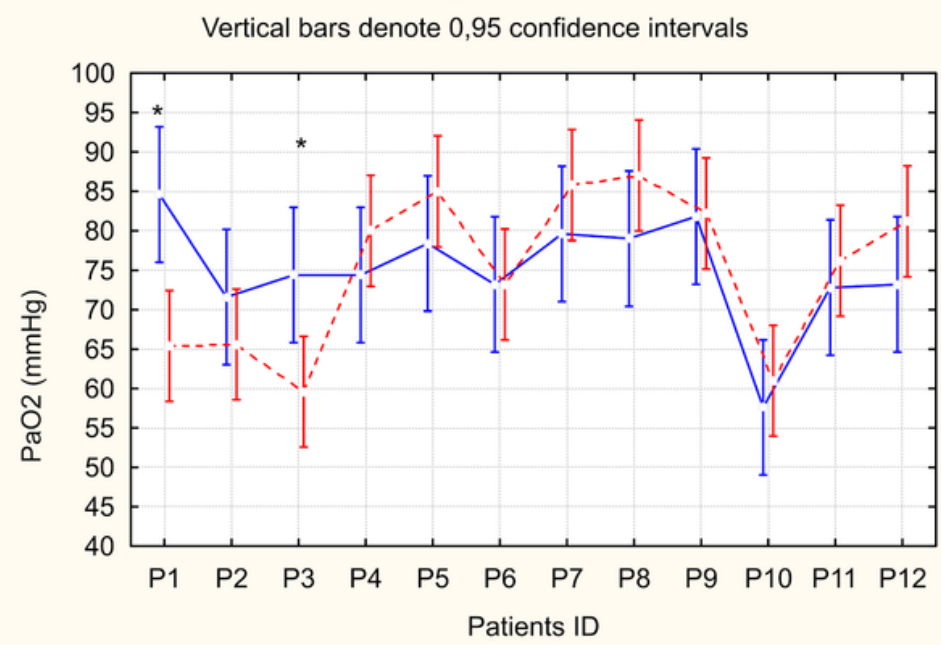

토- NIV

A

DEVICES; LS Means

Current effect: $F(1,48)=0,00799, p=0,92914$

Vertical bars denote 0,95 confidence intervals

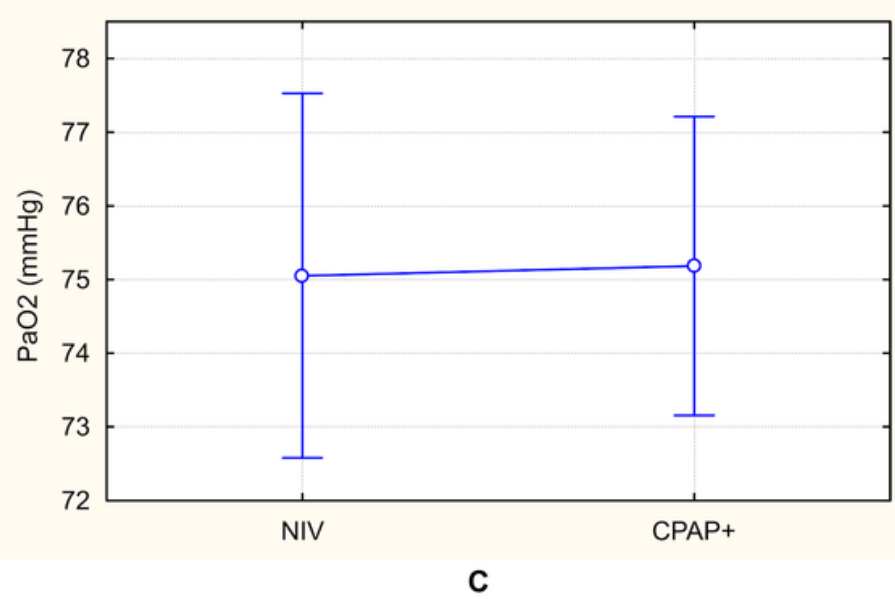

Vertical bars denote 0,95 confidence intervals

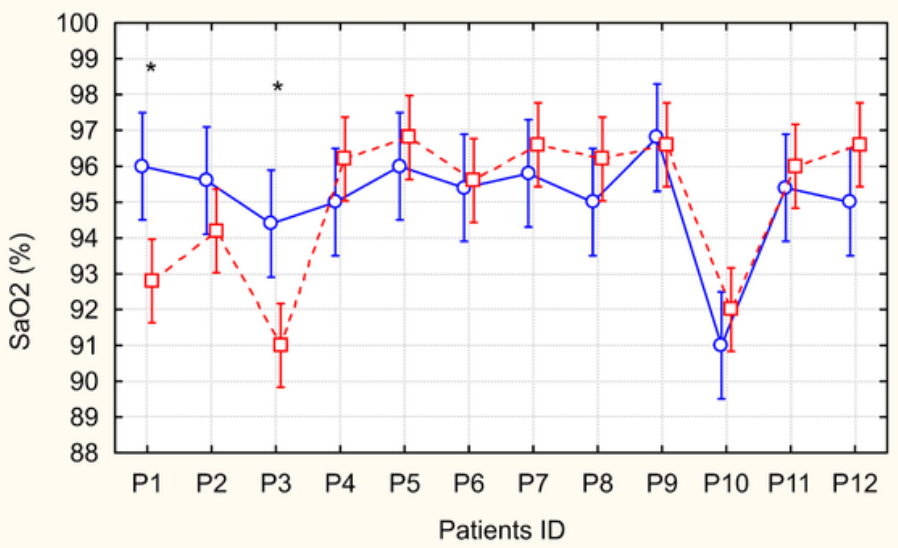

=- NIV

DEVICES; LS Means

Current effect: $F(1,48)=0,0632 p=0,8025$

Vertical bars denote 0,95 confidence intervals

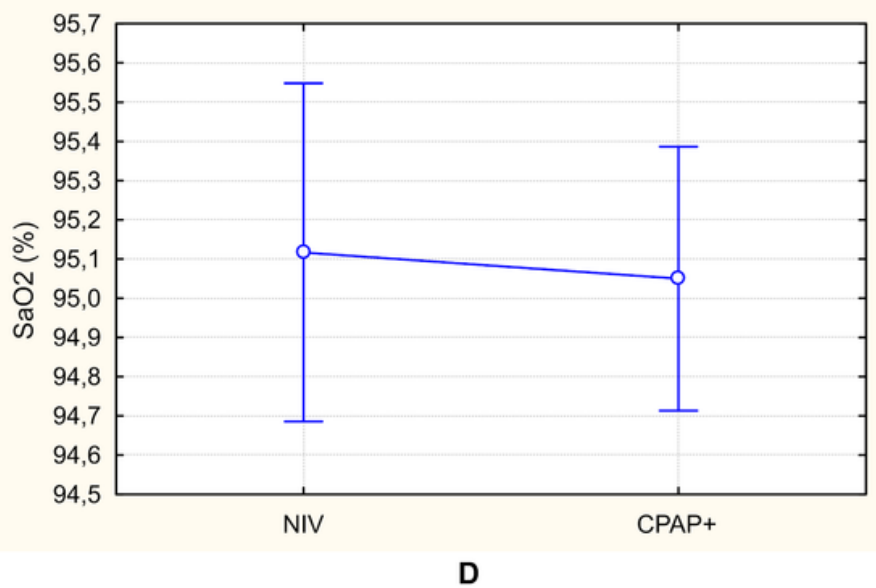

Figure 4

A FiO2 levels necessary to keep oxygen saturation at normal levels in individual patients using two oxygen delivery systems. B. PaCO2 levels in individual patients treated with two compared devices 


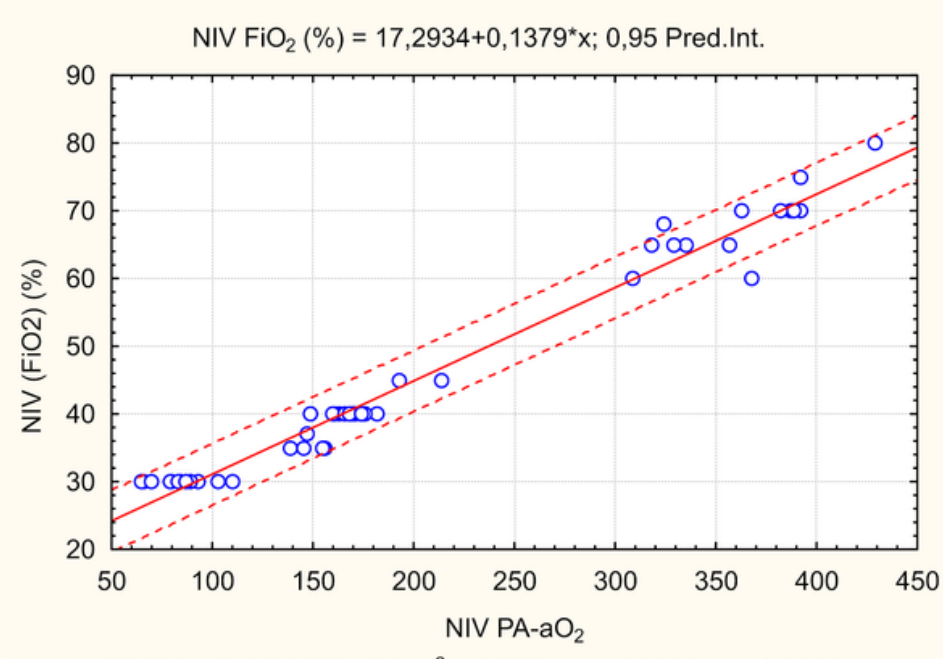

NIV PA-aO $2: \mathrm{NIV} \mathrm{FiO}_{2}(\%): r^{2}=0,9774 ; r=0,9886 ; p=0,0000$;

A

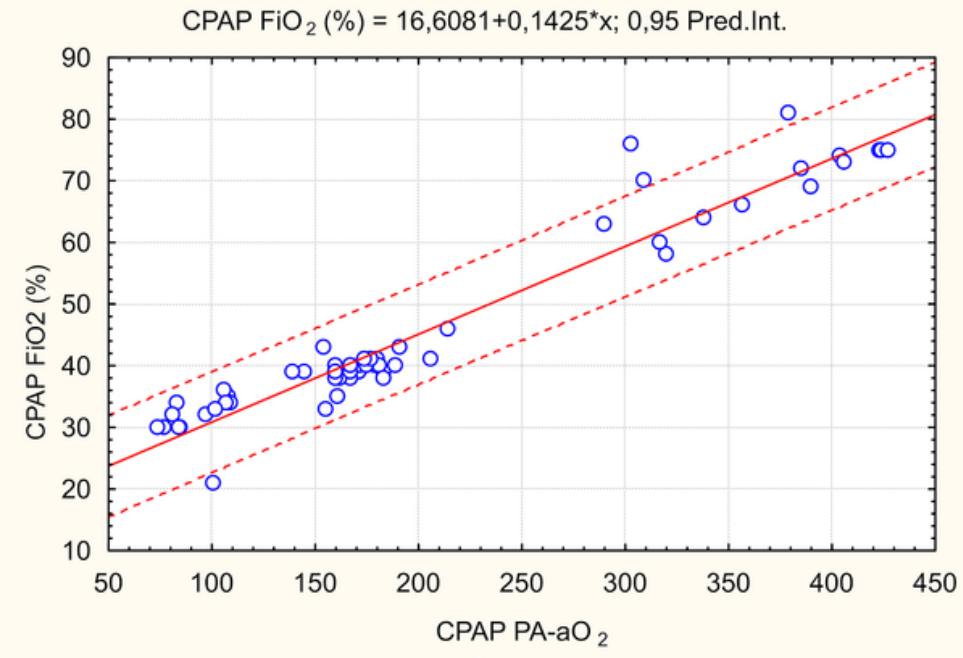

CPAP PA-aO ${ }_{2}: \mathrm{CPAP} \mathrm{FiO}_{2}(\%): r^{2}=0,9312 ; r=0,9650 ; p=0,0000$;

\section{Figure 5}

Regression line with predictive intervals demonstrating the dependence of FiO2 from AaDO2. Data obtained from NIV and CPAP devices 